\title{
INTEGRASI OTENTIKASI ANTARA E-MAIL DAN LINGKUGAN WINDOWS 7 MEMANFAATKAN ZIMBRA-LDAP AND SAMBA
}

\author{
I Wayan Widi Pradnyana \\ Sistem Informasi, Universitas Pembangunan Nasional Veteran Jakarta \\ Jl. RS Fatmawati, Pondok Labu, Cilandak, Jakarta Selatan 12450 \\ widi.pradnyana@gmail.com
}

\begin{abstract}
Abstrak
Jaringan komputer dalam sebuah organisasi membutuhkan integrasi untuk otentikasi dan otorisasi dalam rangka penggunaan sumber daya informasi dan akses komponen infrastrukturnya. Beberapa jenis akses infrastruktur diantaranya adalah akses e-mail dan akses mesin workstation pengguna. Kedua kegiatan akses tersebut secara definisi standard dimungkinkan untuk menggunakan teknologi direktori sebagai representasi data hirarkis. Teknologi LDAP berperan sebagai basis data direktori untuk akses informasi otentikasi sekaligus protokol komunikasinya, sedangkan teknologi SMB berperan untuk proses otentikasi file-sharing dalam lingkungan jaringan Windows. Beberapa penelitian sudah membahas penggunaan LDAP khususnya OpenLDAP eksternal sebagai sebagai teknologi sumber otentikasi khusus untuk beberapa sistem lain seperti : RADIUS, portal, Windows XP, Linux, dsb. Penelitian ini membahas mengenai pemanfaatan Zimbra-LDAP, sebagai LDAP yang sudah terpaket dalam dalam Zimbra Collaboration Suite, menjadi sumber otentikasi, bersama dengan Samba sebagai Domain Controller untuk akses lingkungan Windows 7.
\end{abstract}

Kata Kunci: identity management; authentication; integration; operating system; LDAP; SAMBA; Zimbra

\begin{abstract}
The computer network in an organization requires integration for authentication and authorization in order to use the information resources and its infrastructure components. Some types of infrastructure access include e-mail access and access to computing machines. Both access activities by default are possible to use directory technology as a representation of hierarchical data. LDAP technology as an authentication information directory access database as well as its communication protocol, while SMB technology plays a role in the file-sharing authentication process in Windows network environments. Some studies have discussed the use of LDAP in particular OpenLDAP externally as a technology-specific authentication source for some other systems such as: RADIUS, portal, Windows XP, Linux, etc. This study discusses the use of Zimbra-LDAP, as LDAP already packaged in the Zimbra Collaboration Suite, being the source of authentication, along with Samba as a Domain Controller for Windows 7 environment access.
\end{abstract}

Keywords: identity management; authentication; integration; operating system; LDAP; SAMBA; Zimbra 


\section{PENDAHULUAN}

Sebuah organisasi yang memelihara sumber daya informasi dan infrastruktur akan memiliki kebutuhan untuk memelihara ketergunaannya dan pengelolaanya supaya lebih efektif, disamping aspek lainnya. E-mail dan file sharing adalah sebuah contoh infrastruktur dalam organisasi, yang memiliki sumber daya informasi mencakup informasi pengguna, informasi sumber daya, dan informasi hak akses.

\section{Pustaka Terkait}

Kajian terkait yaitu mengenai manajemen identitas, basis informasi identitas, dan teknologi otentikasi.

\section{Otentikasi Dalam Manajemen Identitas}

Proses Manajemen Identitas didefinisikan berupa rangkaian proses, subyek, dan teknologi yang dibutukan untuk mengelola seluruh siklus identitas dan profil digital. Otentikasi adalah proses untuk memastikan/verifikasi bahwa seseorang adalah memang dirinya . Otentikasi terbagi dalam 2 proses : identifikasi dan verifikasi. Identifikasi adalah pernyataan mengenai siapakah seseorang atau suatu subyek. Verifikasi adalah proses sistem melakukan pemeriksaan ke dirinya bahwa subyek itu adalah memang subyek yang telah dikenali.

\section{Otentikasi Pada Zimbra Sebagai Fasilitas E-mail}

Zimbra sebagai fasilitas e-mail dalam produknya berupa ZCS (Zimbra Collaboration Suite) memiliki beberapa fitur yang menunjang kegiatan kolaborasi komunikasi dalam intranet. Fitur fungsional yaitu message management, shared calendar, shared address book, shared task list. Paket aplikasi ZCS meliputi Zimbra Core, Zimbra Store, Zimbra LDAP, Zimbra MTA, dan sebagainya. Proses otentikasi pada Zimbra dapat menggunakan skema Internal LDAP (OpenLDAP pada Zimbra), External LDAP, External Active Directory, dan Custom Authentication hal 42.

\section{Otentikasi pada Sistem Operasi Windows}

Otentikasi pada Sistem Operasi Windows, baik Windows XP, Windows 2000 , ataupun Windows 7 mendukung single sign-on, dengan menggunakan protokol dasar yaitu Kerberos dan NTLM. Masing-masing produk dapat menggunakan basis informasi dari Active Directory yang umumnya terinsall pada sebuah Domain-Controller, pengelola jaringan berbasis Windows. Produk Active Directory adalah pengembangan dari konsep protokol X.500 dan X.509 yang menjadi basis teknologi LDAP.

\section{Strategi Otentikasi Terintegrasi pada Organisasi}

Strategi otentikasi terintegrasi telah detail dirangkum dalam penelitian Soelaiman .

\section{LDAP sebagai basis informasi dan metode otentikasi}

LDAP dapat dimanfaatkan dalam proses integrasi otentikasi antara sistem operasi Linux dan Windows. Pemanfaatan Zimbra-LDAP dapat digunakan otentikasi LTSP . Teknologi LDAP dapat sebagai pemusatan sistem otentikasi web portal, email Zimbraclient, Windows XP, weblog, proxy/internet access portal Error! Reference source not found.

\section{Samba Sebagai Domain Controller}

Samba adalah suatu aplikasi Unix yang memfasilitasi penerapan protokol SMB (Server Message Block). SMB ini digunakan oleh sistem operasi Windows dan OS/2 untuk proses file-sharing dan 
operasi terkait. Samba dapat dikonfigurasikan sebagai alternatif Domain-Controller, yaitu menyediakan fungsi otentikasi, manajemen dan otorisasi penggunaan sumber daya jaringan .

\section{LDAP-Account-Manager}

Perangkat lunak LDAP-AccountManager (LAM) adalah sebuah sarana, yang sudah tersedia dengan sumber terbuka (open source), dimanfaatkan untuk dapat mengelola akun-akun pada LDAP yang terintegrasi dengan Samba. LDAP.

\section{Metode Penelitian}

Metode penelitian Langkah kerja yang dilakukan ditapilkan pada Gambar berikut :

\section{Analisa Kebutuhan Otentikasi Model Sebelum Integrasi}

Proses awal sebelum integrasi, ditampilkan pada Gambar mencakup 2 kelompok yaitu dari (F1) sisi user atau pengguna fasilitas jaringan tersebut, Proses pada user, seperti gambar 1 ,mencakup : (F1.a) proses otentikasi ke email, (F1.b) proses otentikasi ke terminal Windows, (F1.c) proses penggantian password Zimbra, (F1.d) penggantian password Windows.

Analisa proses dari sisi

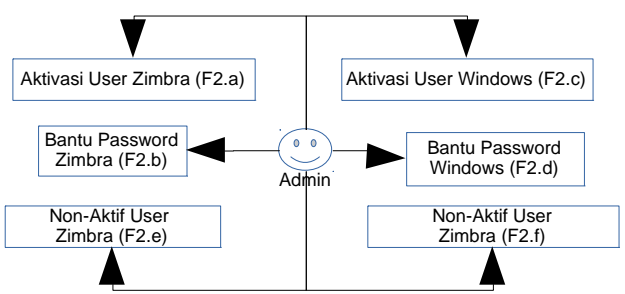

Gambar 1: Proses Admin Pra-Integrasi

administrator (F2) atau pengelola fasilitas, seperti gambar 2 mencakup : (F2.a) aktivasi user Zimbra, (F2.b) pembaruan informasi identitas/password Zimbra(F2.c) pembaruan informasi identitas/password Windows.(F2.d) aktivasi user windows (F2.e) nonaktif user Zimbra (F2.f) nonaktif user Windows.

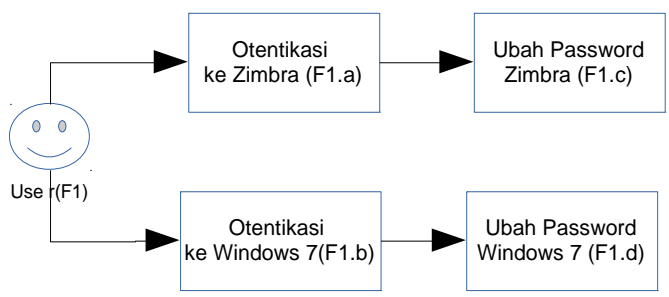

Gambar 3: Proses User Pra-Integrasi

Topologi proses berjalan, seperti pada Gambar, meliputi proses dimana administrator harus mengelola 2 jenis server, yaitu server Zimbra, dan beberapa 
server domain otentikasi untuk Windows 7. Proses ini bersifat duplikatif karena untuk mengelola akun 1 orang dibutuhkan proses yang sama pada lebih dari 2 sistem yang berbeda, mulai dari pembuatan akun, modifikasi akun, penggantian password, dan terminasi akun.

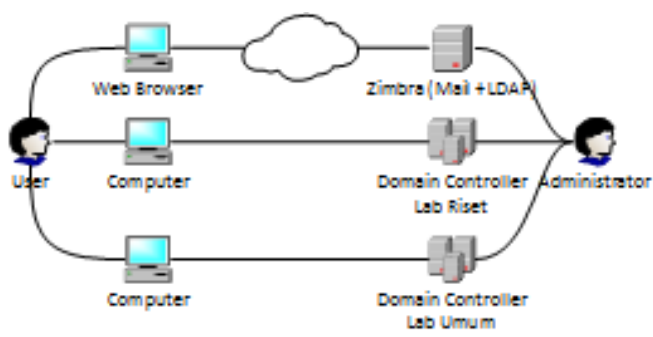

Gambar 4: Topologi Pra-Integrasi

\section{Model Otentikasi Integrasi Usulan}

Penelitian ini mencoba mengusulkan proses baru yang diharapkan memberikan kemudahan baik kepada user/pengguna ataupun kepada administrator/pengelola. Proses yang dicoba diusulkan ditampilkan dalam gambar 4, 5, dan 6 .Proses untuk sisi user (N1) : (N1.a) otentikasi ke Windows, (N1.b) otentikasi ke Zimbra (N1.c) ganti password pada Windows saja, diharapkan password pada email dan LDAP dapat terbarui.

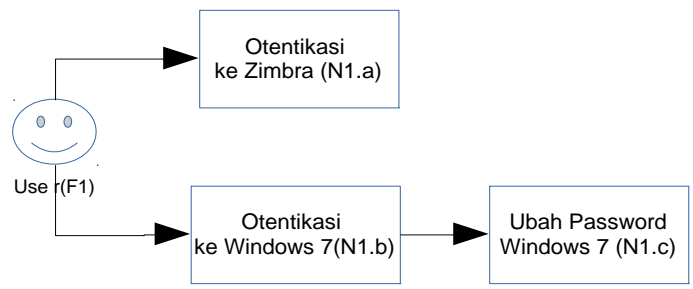

Gambar 5: Proses User Usulan itu dengan menggunakan akun yang sudah diperbarui.

\section{Analisa Teknologi Awal Proses Otentikasi Zimbra}

Proses otentikasi pada Zimbra adalah melakukan query atau ldap search dari modul Zimbra-Mail ke modul Zimbra-LDAP, yang mana sudah otomatis tercakup dan terkonfigurasi pada saat instalasi awal Zimbra Collaboration Suite.

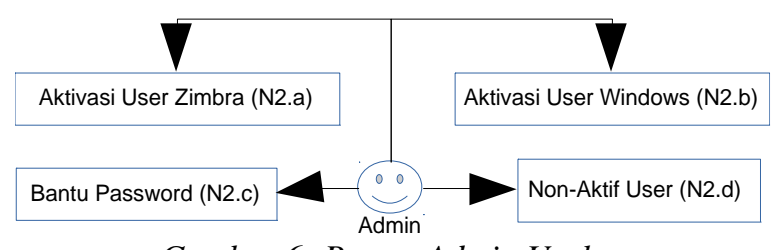

Gambar 6: Proses Admin Usulan

Pada saat sebuah akun baru dibuat pada Zimbra Collaboration Suite, maka akan membuat 1 obyek data pada Zimbra LDAP yang elemen-elemen informasinya terbentuk dari kombinasi objectClass yakni : amavisAccount(auxiliary), inetOrgPerson(structural),

zimbraAccount(auxiliary). Elemenelemen informasi yang diisi sesuai informasi akun adalah : cn, sn, uid, displayName, mail, userPassword, zimbraAccountStatus, zimbraId, zimbraMailDeliveryAddress, zimbraMailHost, zimbraAuthTokenValidityValue, zimbraPasswordModifiedTime, zimbraPasswordMustChange, zimbraMailTransport.

Selanjutnya proses untuk administrator, jika user mengalami lupa password yang menyebabkan tidak bisa login baik pada Windows ataupun Zimbra Email, maka admin dapat melakukan reset password pada 1 buah jalur saja.seperti gambar 6 Diharapkan user bisa login kembali ke 2 lingkunan sistem 


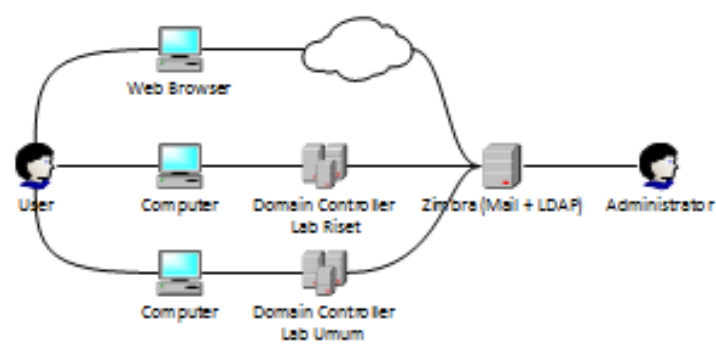

Gambar 7: Topologi Usulan

\section{Struktur Otentikasi Windows + Samba}

Proses otentikasi pada Windows yang terdaftar pada sebuah domain adalah dengan mengakses layanan direktori yang tersedia pada domain controller 104. Sebuah domain controller dapat berupa teknologi Active Directory, umumnya disediakan oleh paket Windows Server, namun juga dapat berupa implementasi SMB oleh Samba Server yang merupakan teknologi berjalan pada platform Linux.

Pada saat sebuah akun baru dibuat untuk Samba, maka akan dibuat 1 obyek data pada LDAP dengan menggunakan objectClass:

person(structural), organizationalPerson(structural), inetOrgPerson(structural), posixAccount(auxiliary), shadowAccount(auxiliary), sambaSamAccount(auxiliary).

Elemen-elemen yang diset adalah : cn, gidNumber, homeDirectory, sambaSID, sn, uid, uidNumber, displayName, givenName, loginShell, sambaAcctFlags, sambaDomainName, sambaHomeDrive, sambaKickoffTime, sambaNTPassword, sambaPrimaryGroupSID, sambaPwdLastSet, shadowExpire, shadowInactive, shadowLastChange, shadowMax, shadowMin, shadowWarning, userPassword, createTimestamp, creatorsName, entryCSN, entryDN, entryUUID, hasSubordinates, modifiersName, modifyTimestamp, structuralObjectClass, subschemaSubentry.

\section{Proses Pengubahan Password Pada Zimbra}

Berikut ini adalah diagram proses pengubahan password oleh user Zimbra.

Pada saat pengubahan password Zimbra, elemen yang berubah adalah : userPassword, zimbraAuthTokenValidityValue, zimbraPasswordModifiedTime.

Elemen-elemen tersebut adalah atribut yang dimiliki oleh objectClass zimbraAccount

\section{Proses Pengubahan Password Pada Windows via Samba}

Proses pengubahan password pada Windows yang terdaftar pada domain controller, akan melakukan modifikasi ke basis data LDAP yang terdapat pada Active Directory ataupun Samba. 104.

Pada saat pengubahan password Samba melalui Windows, elemen-elemen yang berubah adalah : sambaNTPassword, userPassword. Elemen userPassword ini adalah atribut yang dimiliki oleh objectClass zimbraAccount atau turunan objectClass simpleSecurityObject. Sedangkan sambaNTPassword adalah atribut yang dimiliki oleh objectClass sambaSamAccount.

Berdasarkan fakta tersebut, maka tersusun sebuah hipotesa bahwa untuk melakukan integrasi otentikasi maka dibutuhkan beberapa hal sebagai berikut :

1. Dibutuhkan suatu mekanisme yang dapat memfasilitasi agar sebuah akun user dapat memiliki kombinasi objectClass dari Zimbra Email dan Samba

2. Dibutuhkan suatu mekanisme yang dapat memfasilitasi proses pengubahan password oleh user yang dapat membarui passwordnya sekaligus untuk akun akses ke Zimbra Email, dan login ke Windows, dengan 
kondisi bahwa user tersebut sudah terotentikasi sebelumnya.

3. Dibutuhkan suatu mekanisme yang dapat memfasilitasi proses pengubahan password oleh administrator yang dapat sekaligus untuk 2 akun akses yaitu Zimbra Email dan Windows/Samba, dengan kondisi bahwa administrator tidak perlu mengetahui password akun tersebut sebelumnya.

\section{IMPLEMENTASI}

Berdasarkan informasi-informasi dari hasil analisa, berikut ini tahapan yang dilakukan untuk membentuk proses dan topologi baru.

\section{Konfigurasi Zimbra email server Konfigurasi skema LDAP Zimbra}

Skema LDAP Zimbra perlu dimodifikasi untuk bisa men-support otentikasi dari Samba dan informasiinformasi terkait file sharing pada lingkungan Windows. Beberapa file ditambahkan pada sub-direktori instalasi Zimbra

./data/ldap/config/cn=config/cn=schema , sehingga terdapat file-file berikut : d $\mathrm{cn}=\{10\}$ java.ldif, $\mathrm{cn}=\{11\}$ misc.ldif, $\mathrm{cn}=\{1$ $1\}$ misc.ldif,$\quad \mathrm{cn}=\{12\}$ pmi.ldif , $\mathrm{cn}=\{7\}$ samba.ldif , $\mathrm{cn}=\{8\}$ nis.ldif , $\mathrm{cn}=\{9\}$ collective.ldif.

\section{Instalasi dan Konfigurasi}

Samba/Domain Controller

Langkah-langkah konfigurasi dilakukan pada server domain controller untuk memberikan layanan otentikasi dari PC user.

Melakukan konfigurasi pada file /etc/samba/smb.conf

menggunakan konfigurasi yang menggunakan database LDAP yang ada pada Zimbra Server.

Melakukan konfigurasi pada file /etc/smbldap-tools/smbldap.conf smbldap_bind.conf

\section{Konfigurasi Windows 7}

Pada Windows 7 dilakukan modifikasi registry :

$\begin{array}{lll}\text { HKEY_LOCAL_MACHINE } & \rightarrow \\ \text { SYSTEM-> } & \text { CurrentControlSet } & \rightarrow \\ \text { Services -> } & \text { LanmanWorkstation } & \rightarrow \\ \text { Parameters } & & \end{array}$

menambahkan 2 DWORD, masingmasing bernilai

"DNSNameResolutionRequired" $=0$

"DomainCompatibilityMode"=1.

Selanjutnya Windows 7 didaftarkan domain yang didefinisikan pada Samba.

\section{Instalasi dan Konfigurasi LDAP- Account-Manager.}

Untuk dapat memfasilitasi pembuatan user Zimbra, ada instalasi LAM, pada file lam.conf, dilakukan modifikasi, berupa :

- attr_user:

\#uid;\#givenName;\#sn;\#uidNumber;\#g idNumber

- modules_user:

inetOrgPerson, posixAccount,shadow Account,sambaSamAccount,zimbraA ccount,amavisAccount,simpleSecurity Object

\section{EVALUASI}

Evaluasi proses baru dilakukan dengan menguji aspek fungsional dan aspek pengelolaan.

\section{Proses pada User}

\section{Fungsi Login Email Server}

Proses login pada e-mail server dilakukan seperti biasa, otentikasi dengan username dan password.

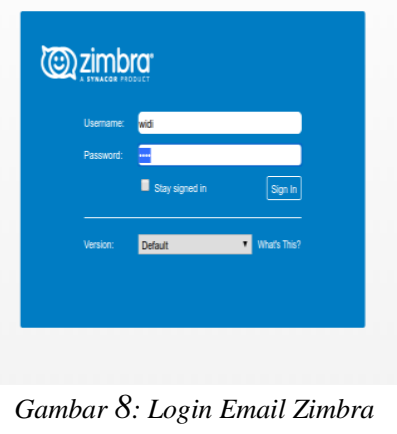




\section{Fungsi Login Ke Windows}

Proses login ke Windows dilakukan dengan mengotentikasi username dan password, dan memilih domain lingkungan Windows 7 dimana user tersebut didaftarkan.
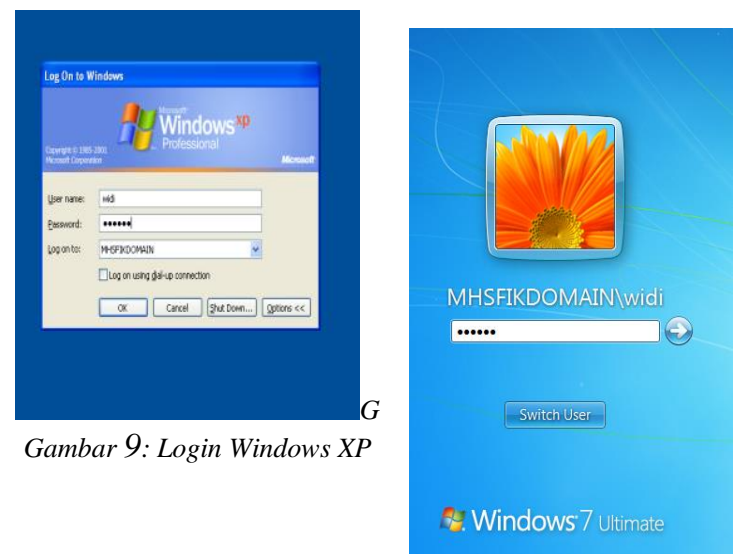

Gambar 10: Login Windows 7

\section{Fungsi Penggantian Password oleh User}

Proses penggantian password oleh user dapat dilakukan pada workstation Windows dimana user tersebut sudah terotentikasi. Proses penggantian password ini akan sekaligus mengganti password NTLM dan sekaligus password LDAP.
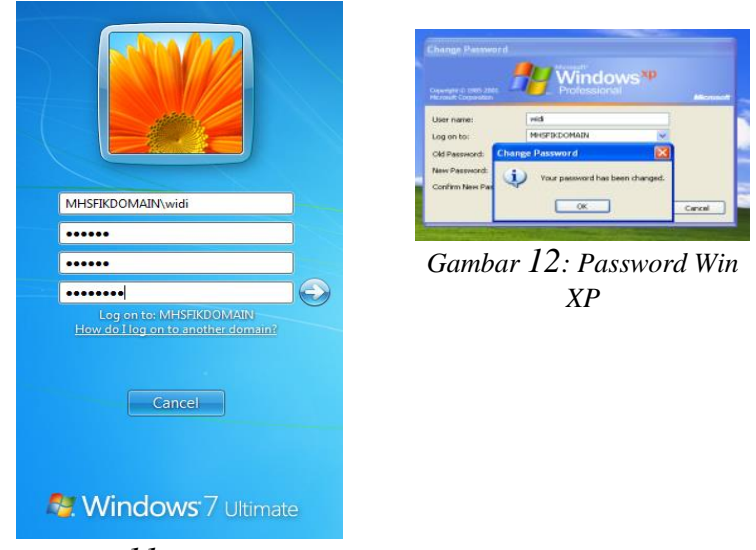

Gambar 11: Passwd Win 7

\section{Proses Administrasi}

\section{Fungsi Pengelolaan User}

Pembuatan Akun User pada Email

Pembuatan akun untuk user dilakukan melalui Zimbra, sehingga pada basis data LDAP tersimpan informasiinformasi yang digunakan untuk mengakses email : seperti nama user, password, domain, dsb.

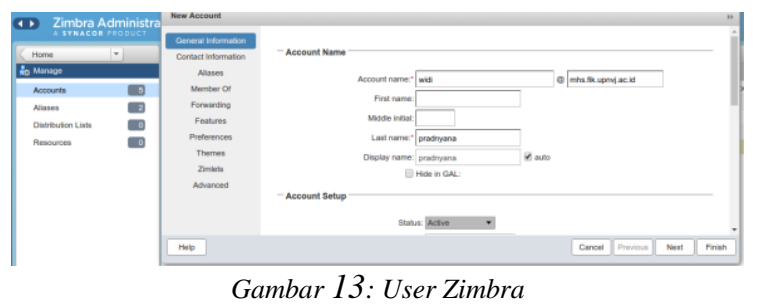

\section{Pembuatan User Jaringan}

Setelah akun user dibuat pada Zimbra-LDAP selanjutnya dapat diakses melalui LAM untuk dilakukan konfigurasi tambahan agar akun tersebut bisa diaktivasi untuk digunakan otentikasi ke lingkungan Windows. Proses aktivasi user dengan menambahkan informasiinformasi yang dibutuhkan oleh SAMBA,

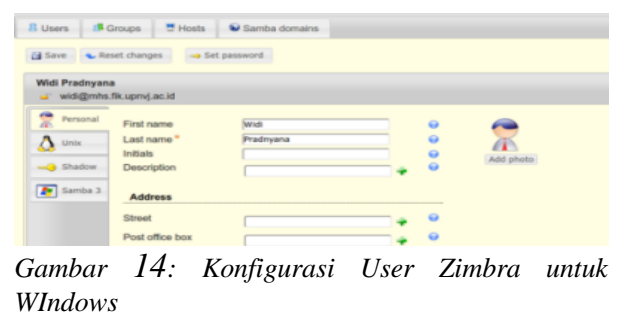

seperti username, profil, home, drive, dsb.

\section{Fungsi Pengalolaan Password oleh Administrator}

Fungsi pengelolaan password ini dilakukan oleh administrator jika ada kebutuhan selama digunakannya akun oleh user. Proses pembaruan password oleh Administrator dilakukan pada modul kelola user pada LAP. Proses ini akan mengganti informasi-informasi password 
yang ada pada password mencakup NTLM dan LDAP password.

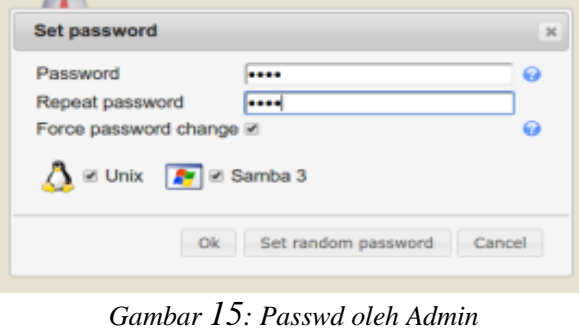

\section{KESIMPULAN DAN SARAN}

Proses evaluasi yang dilakukan telah menunjukkan bahwa rancangan yang dikembangkan dapat memenuhi kebutuhan fungsional akan otentikasi terintegrasi antara Zimbra Email dengan sistem operasi Windows.

Pengembangan lanjutan yang perlu dilakukan yaitu mekanisme otorisasi sebagai pengelolaan hak akses kontrol terhadap sumber daya jaringan. Diharapkan selanjutnya tetap mampu memelihara kesederhanaan proses dengan menggunakan basis informasi otentikasi LDAP.

Ertem Osmanoglu, (2014) "Identity and Access Management : Business Performance Through Connected Intelligence", Ernst \& Young, LLP. Published by Elsevier Inc.

Derrick Rountree (2013), "Federated Identity Primer", Elsevier Inc.

Synacor, Inc, (2016) "Zimbra Collaboration Administrator Guide, Zimbra Collaboration 8.7 Open Source Edition", www.synacor.com 2016

Soelaiman, I Wayan Widi Pradnyana, Wahyu Suadi, (2003) "Analisis dan Perancangan Arsitektur Sistem Otentikasi Terintegrasi”, Jurnal Ilmiah Teknologi Informasi - JUTI ITS, Vol 2 No 2 Juli 2003.

Microsoft Corp (2017), "Windows Authentication", https://technet.microsoft.com/enus/library/cc755284(d=printer,v=ws.1 0).aspx ,

Putera, R.Febrian Satya and Fatchurokhim, Adian and Christyono, Yuli (2011) Sistem Otentikasi Terpusatberbasis Lightweight Directory Access Protocol. Undergraduate thesis, Diponegoro University.

Ahmad Nurul Fajar (2007), "Federated Digital Identity Management Dalam Mendukung E-Business", Jurnal FASILKOM Vol. 5 No.1 Maret, nurul.fajar@lecturer.indonusa.ac.id

I Gede Chandra Kusuma," (2012) Perancangan Dan Implementasi Ldap Pada Ltsp Dan Terintegrasi Dengan Zimbra Ldap", Jurnal Elektronik Ilmu Komputer - Universitas Udayana, JELIKU Vol 1 No. 2 Nopember 2012, igede.chandra@cs.unud.ac.id

Ahmad Herdinal Muttaqin,dkk (2016), "Sistem otentikasi Hotspot Menggunakan LDAP dan Radius pada Jaringan Internet Wireless Prodi Teknik Sistem Komputer", Jurnal Teknologi dan Sistem Komputer, Vol.4, No.2, April 2016 (e-ISSN: 2338-0403) JTsiskom 282, Universitas Diponegoro

David Collier-Brown, Robert Eckstein, Jay Ts, (2003) "Using Samba, Second Edition", O'Reilly.

SK, (2017) "Setup Samba Domain Controller with LDAP Backend in Ubuntu 13.04", https://www.unixmen.com/setupsamba-domain-controller-withopenldap-backend-in-ubuntu-13-04/ diakses 1/16/2017

Roland Gruber Softwareentwicklung (2017), "https://www.ldap-accountmanager.org/static/doc/manual/ch01s 02.html", diakses 15 Januari 2017. 